\title{
In vitro Antibacterial Activity of Mentha spicata Essential Oil against Some Pathogenic Bacteria
}

\author{
Sara I. Othman*, Fouad H. Kamel \\ Department of Medical Laboratory Techniques, Erbil Health Technical College, Erbil Polytechnic University, Erbil, Kurdistan Region, Iraq
}

\begin{abstract}
${ }^{*}$ Corresponding author:
Sara I. Othman, Department of Medical Laboratory

Techniques, Erbil Health

Technical College, Erbil

Polytechnic University, Erbil,

Kurdistan Region, Iraq.

E-mail: sara.othman@epu.

edu.iq
\end{abstract}

Received: 15 June 2020

Accepted: 26 October 2020

Published: 30 June 2021

\section{DOI}

10.25156/pti.v11n1y2021.pp13-15

\section{A B S T R A C T}

Mentha spicata (M. spicata) is within family Lamiaceae that spreads mainly in the temperate and subtemperate zones of the world. It is considered as a good source of essential oils (EOs), which is widely used in food production and pharmaceutical industries. The aim of the current study is to evaluate antibacterial activities associated with the EO of $M$. spicata cultivated in Iraq-Erbil city. The aerial parts of $M$. spicata were subjected to hydro distillation to extract the oil. Antimicrobial potential was tested against many microorganisms, signifying Gram-negative and Gram-positive bacteria. EO of $M$. spicata demonstrated antimicrobial activities with best susceptibility observed for Gram-negative bacteria toward the oil. The results suggest that EO of $M$. spicata may have potential value as antibacterial activities.

Keywords: Antibacterial activities; Ciprofloxacin; Essential oil; Mentha spicata; Pathogenic bacteria

\section{INTRODUCTION}

The spread of drug-resistant pathogenic microorganisms is one of the most serious threats to successful treatment of microbial diseases. Essential oils (EOs) of plants have evoked interest as sources of natural products (Prabuseenivasan et al., 2006). Especially, the antioxidant and antimicrobial activities of EOs as well as their potential anti-cancer activity have been investigated (Zu et al., 2010).

EO have antimicrobial properties that make them suitable alternatives to antibiotics. Recently, the in vitro experiments have demonstrated that EOs or their components could be used favorably to modulate rumen microbial activities (Busquet et al., 2011; McIntosh et al., 2003).

Mentha spicata (spearmint) is within Lamiaceae family grows in throughout the world and this plant is widely employed as a flavoring agent in several foods, also cosmetic, confectionary, and pharmaceutical industries (Kumar et al., 2011) and (Tyagi and Malik, 2011).

Historically, the genus of M. spicata has been applied to treat gastro-intestinal disorders (Tyagi and Malik, 2011).

Carvone and limonene the main components of the EO of M. spicata have been reported to have antibacterial, antioxidant, antiseptic, and antifungal properties (Kumar et al., 2011) and (Telci et al., 2010).

M. spicata is distinguished by its characteristic EO of commercial and therapeutic importance. It is broadly cultivated in many regions worldwide to commercially produce its EO (İşcan, 2002).

Plant EOs have several biological uses, for example, antimicrobial, antioxidant, and antispasmodics, in good correlation with the high contents of phenolic compounds (Shahbazi and Shabisi, 2019).

The aim of the current study was to evaluate antibacterial activities associated with the EO of M. spicata cultivated in Iraq-Erbil city.

\section{MATERIALS AND METHODS}

\section{Materials}

All chemicals that used in this research were in analytical grade and most of them were obtained from Erbil Polytechnic University/Research Centers - Erbil. All reagents and standard solutions were prepared using distilled water.

\section{Collection of Plant Material}

The fresh aerial parts of Mentha plant were gathered from Erbil City at the full flowering stage on July 2018. 
Authentication of the botanical of the plant was conducted by Faculty of Agriculture, Salahaddin University, Erbil, Iraq. The specimen of the collected plant materials was identified as $M$. spicata.

\section{Isolation of the EO}

EO was extracted from the dried aerial parts of M. spicata by hydro-distillation using an instrument of Clevenger type. The extraction was carrying out for $4 \mathrm{~h}$ to mix 200 gram of plants in $1500 \mathrm{~mL}$ of distilled water. The extracts were dried with anhydrous sulfate and concentrated under reduced pressure by rotatory evaporator to evaporate water. The pure oil was stored at $-4^{\circ} \mathrm{C}$ until used. The EOs yield is demonstrated by the oil quality (in $\mathrm{ml}$ ) obtained for $100 \mathrm{~g}$ of dried weight of plant sample.

\section{Stock Antimicrobials Solution}

Stock solution of 1\% Ciprofloxacin in peptone broth media prepared after sterilizing the media by autoclave for $45 \mathrm{~min}$ at $121^{\circ} \mathrm{C}$ and used as positive control.

\section{Test Organism}

Common pathogenic bacterial isolates including Staphylococcus aureus, Staphylococcus epidermidis, Staphylococcus saprophyticus, Streptococcus oralis, Listeria monocytogenes, Pseudomonas aeruginosa, and Pseudomonas fuorescens which isolated from patients were referred to medical lab of Rezgary Hospital-Erbil obtained after diagnosis (Kamel et al., 2014). Bacterial isolates identified by vitek 2 system (Biomerieux company). The cultures of bacteria were maintained on nutrient agar slants at $4^{\circ} \mathrm{C}$ throughout the study.

Microbial suspension with a bacterial count of $1.5 \times 10^{8}$ $\mathrm{CFU} / \mathrm{ml}$ was prepared with normal saline solution (Kamel and Jarjes, 2015). The microbial suspension for each bacterial isolate was cultured on plates containing Brain Heart Infusion Agar and then wells with $6 \mathrm{~mm}$ diameter were created (Kamel et al., 2014).

Four different concentrations of the spearmint EO prepared with Dimethyl Sulfoxide (DMSO) at ratio (2.5\%, $5 \%, 10 \%$, and $20 \%$ ). The tests were done in two replicates and all plates were stored at $37^{\circ} \mathrm{C}$ overnight. The effective concentration of diluted extracted oil against pathogenic bacteria was determined by measuring the inhibition zone of growth comparing to positive control.

\section{RESULTS AND DISCUSSION}

The traditional use of plants as medicines, increasing antibiotic resistance of pathogens, and undesirable side effects of antibiotics suggested the use of Mentha EOs as antibiotics or alternatives for the treatment of various infectious diseases (Zaidi and Dahyia, 2015).

In this research, primary antibacterial effect evaluation of the of M. spicata EO was done utilizing the well diffusion method (Kamel et al., 2013). For each bacterial strain subjected to distinct extract levels, the mean diameter ( $\mathrm{mm}$ ) of the growth inhibition area is shown in Table 1.

The EO of M. spicata was examined for its antibacterial activity potential against a panel of pathogenic microorganisms including Gram-positive and Gramnegative pathogens. M. spicata oil demonstrated variable level of antimicrobial activity against all examined microorganisms. Results obtained by determination zone of inhibition which indicated that the $\mathrm{EO}$ was active especially in concentration (20\%) of Spicata oil against all of them except $S$. saprophyticus.

Our results are in fair correlation with the studies in which spearmint and peppermint oil both showed antibacterial activities against Gram-negative and Gram-positive bacteria (Pattnaik et al., 1997; Singh et al., 2013). The oil also possesses antifungal activity against Aspergillus spp. and Candida albicans. The differences in the antimicrobial activities with the reported one may be due to different geographical environment, age of the plant, different method followed for solation of oil, cultivar type, seasonality, etc.

The results of the current research revealed that the EO exhibited moderate antibacterial effect against the microorganisms. In general, the results of the present study showed that Gram-negative bacteria were more susceptible to $M$. spicata EO than Gram-positive bacteria. Grampositive bacteria, including Staphylococcus aureus, surround

Table 1: Presented effect of EO of M. spicata on microbial growth

\begin{tabular}{|c|c|c|c|c|c|c|c|}
\hline \multirow{2}{*}{$\begin{array}{l}\text { Mentha spicata } \\
\text { essential oil dilution } \\
\text { with DMSO }\end{array}$} & \multicolumn{7}{|c|}{ Inhibition zone measured in $\mathrm{mm}$} \\
\hline & S. aureus & S. epidermidis & S. saprophyticus & S. oralis & $\begin{array}{c}\text { Listeria } \\
\text { monocytogens }\end{array}$ & $\begin{array}{c}\text { Pseudomonas } \\
\text { aeruginosa }\end{array}$ & $\begin{array}{l}\text { Pseudomonas } \\
\text { fluorescens }\end{array}$ \\
\hline $20 \%$ & 6 & 6.5 & 6 & 7 & 7 & 7 & 7 \\
\hline $10 \%$ & 6.7 & 7.5 & 6.5 & 7.5 & 7 & 8 & 7.5 \\
\hline $5 \%$ & 8 & 8.5 & 7 & 8.5 & 8 & 9 & 9 \\
\hline $2.5 \%$ & 6 & 6 & 6 & 6 & 6 & 6 & 6 \\
\hline Ciprofloxacin & 8 & 8.5 & 8 & 9 & 8 & 8.5 & 8 \\
\hline
\end{tabular}


themselves with a thick cell wall that is essential to cell survival and growth and is a major target of antibiotics (Zu et al., 2010).

S. saprophyticus was noted with the highest resistance to the EO, these observations were recently reported by other researchers. Whatever the oil dilution with DMSO $(2.5 \%)$ did not showed activity because of smallest zone of inhibition of S. saprophyticus comparing to others.

\section{CONCLUSION}

In summary, results of the current study revealed that the EO of M. spicata demonstrated moderate bioactivity obtained by its antibacterial potential. These results suggest that the bioactive oil can be beneficially employed in pharmaceutical industries as well as in food production technologies. The discovery of new antibacterial agents was mainly based on natural products that can be obtained from different sources including plants, bacteria, algae, fungi, and animals.

EOs account for a source of very promising natural compounds for producing new antibacterial drugs. Numerous studies have reported a strong antibacterial effect for some EOs. Among these EOs, the potential antibacterial of $M$. spicata has been documented frequently (Vasconcelos et al., 2018).

\section{REFERENCES}

Busquet, M., S. Calsamiglia, A. Ferret and C. Kamel. 2006. Plant extracts affect in vitro rumen microbial fermentation. J. Dairy. Sci. 89: 761-771.

İşcan, G. 2002. Antimicrobial screening of Mentha piperita essential oils. J. Agric. Food Chem. 50(14): 3943-3946.

Kamel, F. H. and S. F. Jarjes. 2015. Essentials of Bacteriology and Immunology. Hawler Polytechnic University, Hawler Technical Health College, Erbil-Iraq.
Kamel, F. H., C. H. Saeed, A. M. Amin and S. S. Qader. 2013. Development of in vitro susceptibility testing for pathogenic bacteria. J. Life Sci. 7(2): 464-467.

Kamel, F. H., C. H. Saeed, A. M. Amin and S. S. Qader. 2014. Magnetic field effect on growth and antibiotic susceptibility of Staphylococcus aureus. Al-Nahrain Univ. J. Sci. 17(3): 138-143.

Kamel, F. H., H. M. Ismael, A. S. Mohammad and S. A. M. Amin. 2017. Approaches for development of new Nano-silver printing ink. Res. J. Pharm. Biol. Chem. Sci. 8(4): 103.

Kumar, P., S. Mishra, A. Malik and S. Satya. 2011. Insecticidal properties of Mentha species: A review. Ind. Crops Prod. 34: 802-817.

McIntosh, F. M., P. Williams, R. Losa, R. J. Wallace, D. A. Beever and C. J. Newbold. 2003. Effects of essential oils on ruminal microorganisms and their protein metabolism. Appl. Environ. Microbiol. 69: 5011-5014.

Prabuseenivasan, S., M. Jayakumar and S. Ignacimuthu. 2006. In vitro antibacterial activity of some plant essential oils. BMC Complement. Altern. Med. 6: 39.

Shahbazi, Y. and N. Shabisi. 2019. Antimicrobial effects of Mentha spicata essential oil and methanolic carrot extract against Staphylococcus aureus and Listeria monocytogenes in fish soup. Pharm. Biomed. Res. 7(1): 32-38.

Singh, C. S. and R. Agarwal. 2013. Evaluation of antibacterial activity of volatile oil from Mentha spicata L. J. Drug Deliv. Ther. 3(4): 120-121.

Telci, I., I. Demirtas, E. Bayram, O. Arabaci and O. Kacar. 2010. Environmental variation on aroma components of pulegone/ piperitone rich spearmint (Mentha spicata L.). Ind. Crops Prod. 32: 588-592.

Tyagi, A. K. and A. Malik. 2011. Antimicrobial potential and chemical composition of Mentha piperita oil in liquid and vapor phase against food spoiling microorganisms. Food Control. 22: 1707-1714.

Vasconcelos, N. G., J. Croda and S. Simionatto. 2018. Antibacterial mechanisms of cinnamon and its constituents: A review. Microb. Pathog. 120: 198-203.

Zaidi, S. and P. Dahiya. 2015. In vitro antimicrobial activity, phytochemical analysis and total phenolic content of essential oil from Mentha spicata and Mentha piperita. Int. Food Res. J. 22(6): 2440-2445.

Zu, Y., H. Yu, L. Liang, Y. Fu, T. Efferth, X. Liu and N. Wu. 2010. Activities of ten essential oils towards propionibacterium acnes and PC-3, A-549 and MCF-7 cancer cells. Molecules. 15: 32003210. 